\title{
STRUCTURE ANALYSIS AND MANUFACTURING OF WINGS TRAINER-5774
}

\author{
Suciari Dewi Widya Triani ${ }^{1}$, Moh.Ardi Cahyono ${ }^{2}$, Lazuardy Rahendra Pinandhita ${ }^{3}$ \\ Program Studi Teknik Dirgantara \\ ${ }^{1,2,3}$ Sekolah Tinggi Teknologi Adisutjipto \\ Jalan Janti Blok R Lanud Adisutjipto, Yogyakarta \\ ${ }^{1}$ suciarid@gmail.com, ${ }^{2}$ mactps774@gmail.com, ${ }^{3}$ lazuardyrp@gmail.com
}

\begin{abstract}
Unmanned Aerial Vechicle (UAV) is one of the types an aircraft. Trainer is part of an airplane where the aircraft is controlled by a remote control for its flight. One of the things that must be considred in design an airplane is strength and and resistance of the wing structure in accepting distributed aircraft loads. In addition to the structural design and load, the material to be used can have an effect. The process is starting from modification of the aircraft wing using CATIA V5R20 which is then carried out analysis of the wing structure by being given the aircraft load using ANSYS 19. The largest structural value is in the Joiner section of 7,967 with manuvering load and smallest value is 0,026 on the Spar section. Margin of safety smallest value in the spar when its manuver. After analysis it is continued with the manufacturing process according to the design that has been made.
\end{abstract}

Keyword: Trainer-5774, analisis sruktur, margin of safety, load factor

\section{Latar Belakang}

Transportasi udara merupakan kebutuhan yang sangat diperlukan di negara kita. Mengingat negara Indonesia terdiri dari ribuan pulau yang membentang dari sabang sampai Merauke. Dalam dunia penerbangan, selain pesawat komersial maupun pesawat militer saat ini mulai berkembangnya pesawat Trainer atau sering disebut pesawat latih. Pesawat ini biasa digunakan oleh aeromodeller yang bertujuan untuk belajar pilot menggunakan Remote Control [1] [2] [3]. Kelebihan pesawat ini adalah mudah dalam pengendaliannya serta mestabilkan diri, selain itu tidak menutup kemungkinan untuk dilakukan modifikasi. Pengembangan dan penelitian ini dilakukan pada pesawat Calmato Alpha Trainer-40 pada bagian sayap pesawat. Pesawat dengan tujuan sebagai pesawat latih memiliki airfoil Clark Y dengan bentuk sayap rectangular. Material yang digunakan pada sayap pesawat Calmato Alpha Trainer-40 adalah strerofoam. Pembuatan pesawat dibutuhkan material yang ringan tetapi kuat, oleh sebab itu material yang disarankan untuk pembuatan pesawat ini adalah komposit dikarenakan jika menggunakan sterofoam pesawat akan mudah patah saat dilakukan penerbangan [4][5]. Komposit merupakan suatu jenis bahan baru dari suatu rekayasa dimana pada saat penggabungan kedua material atau lebih memiliki sifat fisika maupun kimia yang berbeda. Struktur komposit dibagi menjadi 2 yaitu struktur Laminate dan sandwich. Struktur Laminate adalah gabungan dari dua atau lebih lamina dengan arah serat tertentu sedangkan struktur sandwich merupakan komposit yang tersusun dari 3 material yang berbeda yang terdiri dati skin, core dan adhesive sebagai pengikatnya [6][7]. Selain itu agar biaya yang dibutuhkan lebih minim kayu balsa juga digunakan dalam pembuatan pesawat sebagai skin. Industri komposit di luar negeri sudah banyak memakai kayu balsa sebagai bahan skin dari komposit sandwich. Namun di Indonesia kayu ini lebih terkenal sebagai bahan pembuatan aeromodelling dan market [8][9]. Dengan penggabungan secara makroskopis maka keunggulan dari material 
yang digunakan dapat dimanfaatkan. Tujuan penggabungan material yaitu untuk mendapatkan sebuah material yang mempunyai sifat atau keunggulan yang lebih baik.

\section{Metodologi Penelitian}

Pada penelitian ini menggunakan metode pengumpulan data secara studi literatur, Metode Oservasi dan Studi Pustaka. Objek penelitian ini adalah bagian sayap pesawat Trainer-5774. Berikut adalah gambar ilustrasi dari pesawat Trainer-5774 yang akan dilakukan untuk analisis struktur dan manufaktur.
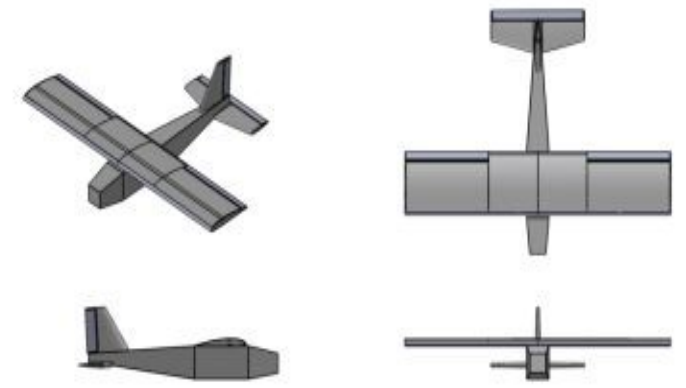

Gambar 1. Pesawat UAV Trainer-5774

Adapun konfigurasi dari pesawat Trainer-5774 adalah sebagai berikut.

Table 1. Konfigurasi Pesawat Trainer-5774

\begin{tabular}{|l|l|}
\hline \multicolumn{1}{|c|}{ Komponen } & \multicolumn{1}{c|}{ Konfigurasi } \\
\hline Main Wing & High Wing, Rectangular \\
\hline Tail Wing & Convensional \\
\hline Airfoil & Wing (Clark Y) Tail (NACA 0012) \\
\hline
\end{tabular}

Data geometri, sistem pesawat dan data wing Trainer-5774 keseluruhan pesawat didapatkan hasil perhitungan sebagai berikut.

Tabel 2. Data Geometri Trainer-5774

\begin{tabular}{|c|c|}
\hline Parameter & Satuan \\
\hline Wing Span & $1,08 \mathrm{~m}$ \\
\hline Wing Area & $0,2268 \mathrm{~m}^{2}$ \\
\hline Taper Ratio & 1 \\
\hline Wing Root Chord & $0,21 \mathrm{~m}$ \\
\hline Wing Tip Chord & $0,21 \mathrm{~m}$ \\
\hline Wing Loading & $3,79 \mathrm{Kg} / \mathrm{m}^{2}$ \\
\hline Fuselage Length & \\
\hline Fuselage Area & $0,77 \mathrm{~m}$ \\
\hline Fuselage Thickness & $0,00847 \mathrm{~m}^{2}$ \\
\hline Vertical Tail Span & $0.11 \mathrm{~m}$ \\
\hline Vertical Tail Area & $0,15 \mathrm{~m}$ \\
\hline Vertical Tail Root Chord & $0,01875 \mathrm{~m}^{2}$ \\
\hline Vertical Tail Tip Chord & $0,17 \mathrm{~m}$ \\
\hline
\end{tabular}




\begin{tabular}{|c|c|}
\hline \multicolumn{2}{|c|}{ Horizontal Stabilizer } \\
\hline Horizontal Tail Span & $0,40 \mathrm{~m}$ \\
\hline Horizontal Tail Area & $0,048 \mathrm{~m}^{2}$ \\
\hline Horizontal Tail Root Chord & $0,14 \mathrm{~m}$ \\
\hline Horizontal Tail Tip Chord & $0,10 \mathrm{~m}$ \\
\hline \multicolumn{2}{|c|}{ Rudder } \\
\hline Rudder Span & $0,15 \mathrm{~m}$ \\
\hline Rudder Area & $0,000675 \mathrm{~m}^{2}$ \\
\hline Rudder Chord & $0,045 \mathrm{~m}$ \\
\hline \multicolumn{2}{|c|}{ Elevator } \\
\hline Elevator Span & $0,38 \mathrm{~m}$ \\
\hline Elevator Area & $0,0133 \mathrm{~m}^{2}$ \\
\hline Elevator Chord & $0,035 \mathrm{~m}$ \\
\hline \multicolumn{2}{|c|}{ Aileron } \\
\hline Aileron Span & $0,36 \mathrm{~m}$ \\
\hline Aileron Area & $0,0108 \mathrm{~m}^{2}$ \\
\hline Aileron Chord & $0,03 \mathrm{~m}$ \\
\hline$W_{T O}$ & $8,44 \mathrm{~N}$ \\
\hline
\end{tabular}

Tabel 3. Sistem Pesawat Trainer-5774

\begin{tabular}{|l|c|}
\hline Sistem & Berat Sistem (Kg) \\
\hline Motor Brushless 2212 2200 kv & 0,0047 \\
\hline ESC 40A & 0,043 \\
\hline Receiver FrSky & 0,01 \\
\hline 4 Servo Digital & 0,048 \\
\hline Battery 5000mAh 7.4 V & 0,275 \\
\hline Propeller 11x7 & 0,016 \\
\hline Total W system & 0,3967 \\
\hline
\end{tabular}

Tabel 4. Data Wing Trainer-5774

\begin{tabular}{|l|c|c|}
\hline \multicolumn{1}{|c|}{ Parameter } & Symbol & Nilai \\
\hline Airfoil & - & Clark Y \\
\hline Aspect Ratio & AR & 5,1 \\
\hline Wing Area & $\mathrm{Sw}$ & $0,2268 \mathrm{~m}^{2}$ \\
\hline Wing span & $\mathrm{Bw}$ & $1,08 \mathrm{~m}$ \\
\hline Wing chord & $\mathrm{Cw}$ & $0,21 \mathrm{~m}$ \\
\hline
\end{tabular}




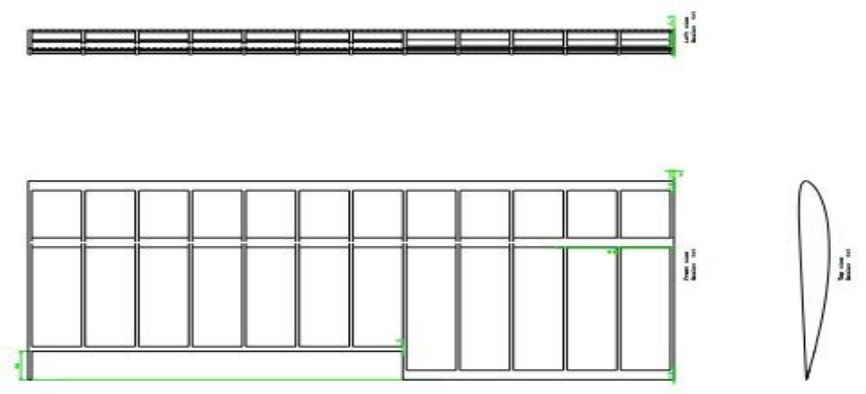

Gambar 2. Design Wing Trainer-5774

\section{Hasil dan Pembahasan}

Pada bab ini akan dibahas mengenai hasil analisis struktur menggunakan software Catia V5R20 dan ANSYS R19.0 untuk menghitung kriteria kegagalan komposit (Failure criteria).

\subsection{Kajian Pemilihan Material}

Material pada sayap pesawat Calmato Alpha Trainer-40 adalah Sterofoam. Penulis melakukan modifikasi material pada sayap pesawat menggunakan kayu balsa yang diperkuat dengan komposit serat karbon. Hal itu dikarenakan pada material pesawat sebelumnya mudah patah jika pesawat melakukan manuver. Kondisi dilapangan sangat sering terjadi pesawat yang terbuat dari sterofoam akan mudah hancur saat pesawat mengalami gagal take-off atau gagal manuver dan sangat sulit jika dilakukan perbikan. Sehingga dilakukan modifikasi material menggunakan balsa dan serat karbon karena material tersebut lebih kuat dan ringan jika dibandingkan sterofoam [9][10][11].

\subsection{Hasil Analisis Struktur Wing Kondisi MTOW}

Hasil analisis struktur wing pada kondisi MTOW adalah hasil dari sayap pesawat yang diberikan beban secara distribusi sebesar 4,22 N. Maksimum stress yang terjadi pada bagian sayap Trainer-5774 adalah sebesar 58,505 MPa.

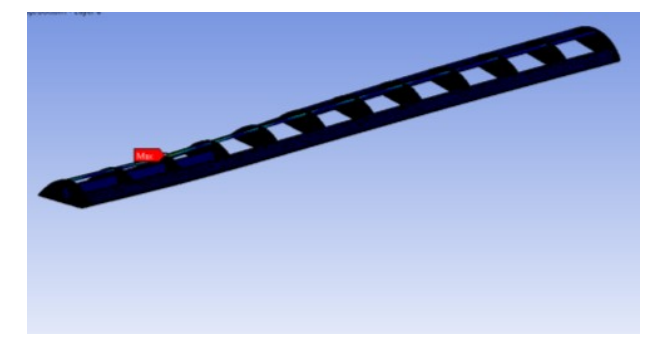

Gambar 3. Von Mises Stress Sayap Pesawat Trainer-5774

\subsection{Hasil Analisis Struktur Wing Kondisi Manuver}

Pada analisis ini pesawat diasumsikan terbang pada kondisi manuver. Berdasarkan regulasi pesawat UAV negara Australia (C.A.S.A. Australia Subpart C - Structur UA25.33.7), pembebanan diterapkan pada kondisi ini. Beban yang di asumsikan sebagai load factor sebesar 2 yang dikalikan dengan berat MTOW Trainer-5774. 


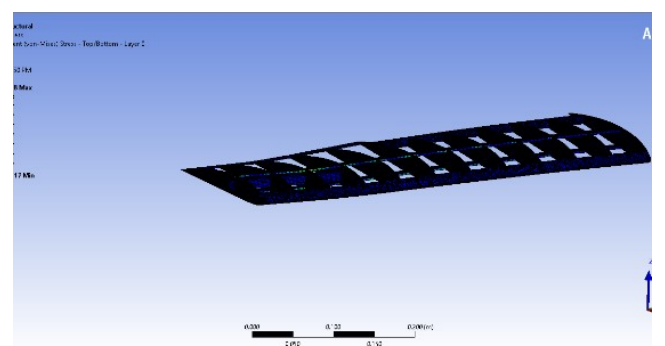

Gambar 4. Von Mises Stress Sayap Pesawat Trainer-5774 dengan n=2

Dari hasil analisis di atas diperoleh hasil maksimum stress pada sayap pesawat Trainer 5774 dengan diberi beban kondisi manuver sebesar 8,44 N adalah sebesar 119,27 $\mathrm{MPa}$.

\subsection{Failure criteria}

Perhitungan Failure criteria dan margin of safety dari suatu struktur bertujuan untuk mengetahui apakah suatu struktur aman jika di berikan beban tertentu dengan menggunakan bahan tertentu. Dengan melihat apakah beban yang diberikan tidak melebihi dari batasan suatu material. Berikut adalah hasil dari Failure criteria dan margin of safety sayap pesawat Triner5774:

a. Kondisi MTOW

Berikut adalah perhitungan Failure criteria pada saat pesawat take-off pada bagian masing-masing struktur.

$$
\begin{gathered}
\left(\frac{\sigma_{1}}{x}\right)^{2}-\frac{\sigma_{1} \cdot \sigma_{2}}{x^{2}}+\left(\frac{\sigma_{2}}{y}\right)+\left(\frac{\tau_{12}}{s}\right)^{2} \leq 1 \\
\left(\frac{12496}{6669000}\right)^{2}-\frac{12496 * 38968}{6669000^{2}}+\left(\frac{38968}{1549451}\right)+\left(\frac{66356}{1823056,2}\right)^{2} \leq 1 \\
0,023 \leq 1
\end{gathered}
$$

Perhitungan Margin of Safety pada material sayap pesawat Trainer-5774 adalah sebagai berikut.

$$
\begin{aligned}
\mathrm{Ms} & =\frac{\sigma \text { all }}{\sigma a p p}-1 \\
& =\frac{6669000 \mathrm{MPa}}{116080 \mathrm{MPa}}-1 \\
& =56,451
\end{aligned}
$$

Dari proses perhitungan didapatkan Failure criteria dan margin of safety dari setiap lapisan yang berbahan komposit sebagai berikut.

Tabel 5. Failure criteria dan margin of safety Joiner Kondisi MTOW

\begin{tabular}{|c|c|c|}
\hline Lapisan Joiner & Margin of Safety & Failure criteria \\
\hline Balsa1 & 56,451 & - \\
\hline Karbon1 & - & 0,3818174 \\
\hline Karbon2 & - & 0,3864264 \\
\hline Karbon3 & - & 0,3909835 \\
\hline Karbon4 & - & 0,3954123 \\
\hline
\end{tabular}




\begin{tabular}{|c|c|c|}
\hline Karbon5 & - & 0,4000062 \\
\hline Karbon6 & - & 0,4044383 \\
\hline Balsa2 & 56,417 & - \\
\hline
\end{tabular}

Tabel 6. Failure criteria dan margin of safety Spar Kondisi MTOW

\begin{tabular}{|c|c|c|}
\hline Lapisan Joiner & Margin of Safety & Failure criteria \\
\hline \multicolumn{3}{|c|}{ Spar Atas } \\
\hline Balsa & 9,483 & - \\
\hline Karbon & - & 0,0677532 \\
\hline Karbon2 & - & 0,1913341 \\
\hline Balsa & Spar Bawah \\
\hline Karbon & 9,715 & - \\
\hline Karbon2 & - & 0,2033728 \\
\hline
\end{tabular}

b. Kondisi Manuver

Berikut adalah perhitungan Failure criteria dan margin of safety pada saat pesawat melakukan manuver dengan $n=2$ :

$$
\begin{gathered}
\left(\frac{\sigma_{1}}{x}\right)^{2}-\frac{\sigma_{1} \cdot \sigma_{2}}{x^{2}}+\left(\frac{\sigma_{2}}{y}\right)+\left(\frac{\tau_{12}}{s}\right)^{2} \leq 1 \\
\left(\frac{25474}{6669000}\right)^{2}-\frac{25474 * 79442}{6669000^{2}}+\left(\frac{79442}{1549451}\right)+\left(\frac{135280}{1823056,2}\right)^{2} \leq 1 \\
0,057 \leq 1
\end{gathered}
$$

Perhitungan Margin of Safety pada material sayap pesawat Trainer-5774 adalah sebagai berikut.

$$
\begin{aligned}
\text { Ms } & =\frac{\sigma \text { all }}{\sigma a p p}-1 \\
& =\frac{6669000 M P a}{236640 M P a}-1 \\
& =27,182
\end{aligned}
$$

Dari proses perhitungan didapatkan Failure criteria dan margin of safety dari setiap part yang berbahan komposit sebagai berikut.

Tabel 7. Failure criteria dan margin of safety Joiner Kondisi Manuver

\begin{tabular}{|c|c|c|}
\hline Lapisan Joiner & Margin of Safety & Failure criteria \\
\hline Balsa1 & 27,182 & - \\
\hline Karbon1 & - & 0,7782516 \\
\hline Karbon2 & - & 0,7874841 \\
\hline Karbon3 & - & 7,9677624 \\
\hline Karbon4 & - & 0,8067021 \\
\hline
\end{tabular}




\begin{tabular}{|c|c|c|}
\hline Karbon5 & - & 0,8157677 \\
\hline Karbon6 & - & 0,8260421 \\
\hline Balsa2 & 27,054 & \\
\hline
\end{tabular}

Tabel 8. Failure criteria dan margin of safety Spar Kondisi Manuver

\begin{tabular}{|c|c|c|}
\hline Lapisan Joiner & Margin of Safety & Failure criteria \\
\hline \multicolumn{3}{|c|}{ Spar Atas } \\
\hline Balsa & 4,142 & - \\
\hline Karbon & - & 0,0677532 \\
\hline Karbon2 & - & 0,1913341 \\
\hline Balsa & Spar Bawah \\
\hline Karbon & 4,256 & - \\
\hline Karbon2 & - & 0,2033728 \\
\hline
\end{tabular}

\section{Kesimpulan}

Data yang diperoleh pada hasil analisis struktur metode berdasarkan perolehan data yang dilakukan secara konvergensi. Hasil dari analisis maksimum stress pada sayap pesawat sebesar 58,505 MPa pada kondisi MTOW dan 119,7 MPa kondisi manuver. Maksimum stress analisis struktur terbesar terletak pada bagian Spar yaitu sebesar 55,476 MPa pada Spar bawah saat diberi beban setengah MTOW 4,22 N dan 118,21 MPa pada Spar atas saat beban manuver dengan beban 8,44 N.Pada perhitungan Failure criteria didapatkan hasil Spar terkecil 0,04 pada bagian Spar atas sayap pesawat Triner-5774 pada pemberian beban MTOW dan terbesar 0,420 pada bagian Spar bawah beban manuver. Sedangkan pada bagian Joiner terkecil yaitu 0,026 pada bagian balsa dengan beban MTOW, Failure criteria terbesar pada kondisi pembebanan manuver yaitu 7,967 dan terjadi kegagalan struktur atau tidak aman.Pada proses manufaktur pesawat dirancang berdasarkan goemetri pemodelan. Perbedaan ukuran terjadi pada bagian panjang joiner yang tidak sesuai ukuran geometri yang menyebabkan longgarnya sayap saat disatukan. Hal tersebut dikarenakan pembuatan dilakuakan secara hand made dan masih masuk pada batas toleransi ukuran. Sayap pesawat dirancang secara modular (lepas pasang) guna mempermudah dalam proses manufaktur maupun pemasangan. Selain itu jika terjadi kerusakan atau kegagalan pada bagian sayap pesawat terbang tidak sulit dalam melakukan perbaikan.

\section{Daftar Pustaka}

[1] Astasari.2017. Pengaruh Variasi Arah Serat Dan Jumlah Layer Terhadap Karakteristik Bending Dan Torsional Stiffness Komposit Sandwich Serat Karbon Dengan Core Kayu Balsa, Institut Teknologi Sepuluh November, Surabaya.

[2] Civil Aviation Safety Authority Australia, (2000). Design Standards: Unmanned Aerial Vehicles - Aeroplanes. 2000.

[3] Gibson, Ronald F.1994. Principle Of Composite Material Mechanics.United States of America, Amerika.

[4] Kurniawan. M . H, 2017. Analisis Kekuatan Wing Pesawat UAV MAC 01 Terhadap Bending Dan Torsi, Sekolah Tinggi Teknologi Adisutjipto, Yogyakarta.

[5] Martin, J . W. 2006. Materials For Engineering, Boca Raton Boston New York Washington, DC. 
[6] Mohammadi, Meisam Shir dan Nairn,John A. 2014. Crack propagation and fracture toughness of solid balsa used for cores of sandwich composites, Oregon State University, USA.

[7] Mokhtar, M., Rahmat, A . R., Hassan, A. 2007. Characterization And Treatments of Pineapple Thermoplastic Composite For Construction Application. Universitas Teknologi Malaysia, Malaysia.

[8] Niu, Michael Chun-yung. 1998. Airframe Structural Design. Conmilit Press Ltd, California.

[9] Pecas, P., Cavalho, H., Salman H., Leite, M. 2018. Journal of Composite Science, Portugal.

[10] Purboningrum, S.C.2020. Modifikasi Dan Manufaktur Batang Vtol ( Vertical Take Off Landing ) Pesawat UAV V-Sky STTA, Sekolah Tinggi Teknologi Adisutjipto, Yogyakarta.

[11] Saputra, W . E. 2019. Modifikasi UAV V-SKY 14 Dan Analisis Kekuatan Struktur Sayap, Fuselage, Dan Tail UAV V-SKY 14 NG Menggunkan Software MSC Patran/Nastran, Sekolah Tinggi Teknologi Adisutjipto, Yogyakarta. 